\title{
Letrōnica
}

\section{O kotel como palimpsesto, o verbo e a fé na narrativa em "Milagre secreto"}

\section{The kotel as a palimpsest: the word and faith in "The secret miracle"}

Aline Coelho da Silva

Doutora em Letras pela UFRGS (2007) é professora adjunta na Universidade Federal de Pelotas, onde atua no ensino espanhola.

E-mail: silva.aline.coelho@gmail.com
RESUMO: Trataremos de dois temas inesgotáveis por essência, a Kabbalah e a obra de Jorge Luis Borges. Dois caminhos, um derivado de outro, cuja fortuna crítica é abrangente ao extremo. Optaremos por uma perspectiva da teoria da narrativa em Borges, nesse sentido, visitaremos brevemente o conceito do que seja a Kabbalah principalmente para o escritor argentino, revelado singular em textos ensaísticos e ficcionais e em sua relação com G. Scholem, que levou o tema da Sabedoria Sagrada à academia, e com seus demais críticos. Em um segundo momento, tentaremos demonstrar como a fé se articula na revelação do fantástico em Milagre secreto, conto do livro Ficções, de 1944.

PALAVRAS-chave: Borges; Kabbalah; Fé; Kotel; Milagre secreto

ABSTRACT: We will address two inexhaustible themes in essence, the Kabbalah and the work of Jorge Luis Borges. Two paths, one derived from another, whose critical fortune is comprehensive to the extreme. We will opt for a perspective of narrative theory in Borges, accordingly, briefly visit the concept of what is Kabbalah mainly to the Argentine writer, revealed in essayistic and fictional texts and in its relationship to G. Scholem, who took the theme of Sacred Wisdom to the academy, and with its other critics. In a second moment we will try to show how faith is articulated in the revelation of the fantastic in Secret Miracle, a tale from the book Fictions, 1944.

KEYworDs: Borges; Kabbalah; Faith; Kotel; The secret miracle
"Las generaciones de Israel estaban en ti cuando me dijiste sonriendo: Je suis tres fatigué. J'ai quatre mille ans."

(BORGES. Elegía. 2005, s.p.) 
Torá se inscreve na tradição como um livro sagrado, cuja escrita está cifrada em níveis diversos de entendimento, narrativas com histórias de fieis, linguagem alegórica, exposição de leis que geraram os dogmas judaicorabínicos e, por fim, seu caráter secreto, ao qual se dedicam os cabalistas. Esta revelação do Criador ao homem através da escritura reitera a relação entre divindade e linguagem, é "um mundo de nomes divinos que se abrem de acordo com uma lei que lhes é própria. Os elementos da linguagem divina aparecem como as letras das Escrituras Sagradas. Letras e nomes não são apenas meios convencionais de comunicação. São muito mais" (SHOLEM, 2012, p. 48).

Assim, o princípio do nome de Deus, o da Torá como um organismo e o princípio do significado infinito da palavra divina são, segundo o teórico, os princípios fundamentais da Kabbalah que, então, será basicamente uma técnica de leitura do texto sagrado. Em Do culto aos livros (2007), Borges rememora Bloy ao dizer que "somos versículos ou palavras ou letras de um livro mágico, e esse livro incessante é a única coisa que há no mundo: melhor dizendo, é o mundo" (p. 136), relação que veremos explicitada quando se refere ao Universo como Biblioteca, no conto La biblioteca de Babel:

(Los místicos pretenden que el éxtasis les revela una cámara circular com un gran libro circular de lomo continuo, que da toda la vuelta de las paredes; pero su testimonio es sospechoso; sus palabras oscuras. Ese libro cíclico es Dios). Básteme, por ahora, repetir el dictamen clásico: La Biblioteca es una esfera cuyo centro cabal es cualquier hexágono, cuya circunferencia es inaccesible (BORGES, 2014. p. 90)

Nessa perspectiva, a Criação se afirma, em seu discurso, como uma elaboração da linguagem divina expressa em um livro, que é a biblioteca, que é o Universo. Essas proposições localizam Borges como leitura indispensável no entendimento da própria noção de intertextualidade, como veremos, e reafirmam sua noção de linguagem compartilhada com a dos cabalistas $^{1}$. Suas raízes judaicas são uma filiação de afeto a uma tradição de culto à palavra e aos livros, como aclara em Yo, judío, publicado em 1934:

¿Quién no jugó a los antepasados alguna vez, a las prehistorias de su carne y su sangre? Yo lo hago muchas veces, y muchas no me disgusta pensarme judío. Se trata de una hipótesis haragana, de una aventura sedentaria y frugal que a nadie perjudica, ni siquiera a la fama de Israel, ya que mi judaísmo era sin palabras (BORGES, 1934. p. 60).

Sua memória biográfica é, como aponta Piglia² ${ }^{2}$ o cruzamento da memória narrativa, fabulada, e da vasta tradição literária que consumiu, provocando, em sua ficção, contradições, argumentos e deslocamentos que são seu próprio estilo. É o que Nascimento observa sobre sua estratégia de escrita de reorganização da ordem do arquivo da tradição: "recorta o material de que necessita para engendrar um outro texto, (...) desterritorializa essa tradição tal como ela é concebida, reinventando-a em outro espaço-tempo" (2009, p. 19).

Essa "reorganização" das categorias talvez tenha sido o que inspirou Foucault a desenvolver As palavras e as coisas ${ }^{3}$, como aponta em seu prefácio, mas cabe também lembrar de A memória de Shakespeare (BORGES, 2011) em que tal articulação trata da tradição da literatura em seu mosaico de citações, apropriações e, como tal, da tradução (e não exatamente criação) do Universo (biblioteca) já estabelecido. Assim entenderemos a noção de

${ }^{1}$ O primeiro contato de Borges com a Kabbalah teria sido na leitura da introdução de Longfelow para A divina comédia, conforme relata em entrevista a Sosnowski, em 1971. Conforme NASCIMENTO, 2009. p. 33

2 Em Ideología y ficción en Borges (1979), Piglia afirma que "La memoria y la biblioteca representan las propiedades a partir de las cuales se escribe, pero esos dos espacios de acumulación son, a la vez el lugar mismo de la ficción en Borges" (p. 5).

3 Diz Foucault que seu livro nasceu de um texto de Borges: "Do riso que, com sua leitura, perturba to Foucault que seu livro nasceu de um texto de Borges: "Do riso que, com sua leitura, perturba to tornam sensata para nós a profusão de seres, fazendo vacilar e inquietando, por muito tempo, nossa prática milenar do Mesmo e do Outro"
(2002. p. IX). 
escrita como de tradução ${ }^{4}$ de sua tradição (na qual é inscrito e na qual quer inscrever-se), de sua anterioridade, em uma proliferação de intertextos e leituras das quais derivam o entendimento de narrativa para o bibliotecário cego: um livro que cria e é o Universo criado no qual todas as coisas já estão. Ao receber a memória de Shakespeare o narrador asserta: "De Quincey afirma que o cérebro do homem é um palimpsesto. Cada nova escrita recobre a escrita anterior e é recoberta pela anterior" (BORGES, 2011. p. 96).

No alto do Monte Moriá está um dos mais importantes símbolos judaicos, o Kotel, o Muro das Lamentações; mais que um símbolo, o Kotel é um lugar sagrado, pois é a parte restante do Segundo Templo, destruído no ano 70, pelos romanos. É “a eternidade de D’us e do Povo Judeu escrita em pedra", um muro cujas fissuras são preenchidas circularmente (pelo devir do tempo, dos ventos, da chuva e do pó) pelos papeis calcados pelos fieis, cujo número infinito, talvez determinado ${ }^{6}$ de palavras cujo único leitor seria o Criador dão sustentação à tradição através das letras às quais cada um corresponde. Essa imagem nos remete ao palimpsesto como estratégia e intertexto indissociável ao fazer literário em Borges.

Em seu ensaio Palimpsestos ${ }^{7}$, escrito em 1981, Genette busca tratar da transtextualidade, que define como a própria literariedade da literatura, ou seja, tudo o que transcende ao próprio texto, "tudo que o coloca em relação,

${ }^{4}$ Ver em Raúl Antelo o conceito de tradição e tradução em: ANTELO, Raúl. Os contextos da tradição universal. Revista Brasileira de Literatura Comparada. Florianópolis, n. 4, p. 61-74, 1998.

In: <http://www.pt.chabad.org/library/article_cdo/aid/2760853/jewish/O-Muro-das-Lamentaes.htm>. Acesso em: 30 mar. 2014. Tamanha é a importância do Kotel para a comunidade, que há imagens 24 horas ao vivo pela internet. Veja em: <http://english.thekotel.org/?catid=\%7BD0A9DD10-5753-44F3A5C0-D692097D8875\%7D>.

6 Em Argumentum ornthologicum a problemática é evidenciada para comprovar a existência do Criador: “(..) Si Dios existe, el número es definido, porque Dios sabe cuántos pájaros vi. Si Dios no existe, el (... Si Dios existe, el número es á (.) Ese número entero es inconcebible;

Cujo título talvez seja inspirado em Pierre Menard, autor de Ouixote. manifesta ou secreta com outros textos" (p. 7). Sua tese compreende a noção de Borges de palimpsesto no qual não há o esquecimento:

Ainda é necessário nos ocuparmos da hipertextualidade que tem em si mesma o mérito específico de relançar constantemente as obras antigas em um novo circuito de sentido. A memória, se diz, é "revolucionária" - certamente contanto que a fecundemos, e que ela não se contente em comemorar. "A literatura é inesgotável pela única razão de que um único livro o é". Este livro não deve apenas ser relido, mas reescrito, como Ménard, literalmente. Também se completa a utopia borgesiana de uma Literatura em transfusão perpétua - transfusão transtextual - constantemente presente em si mesma na sua totalidade e como Totalidade, cujos autores todos são apenas um, e todos os livros são um vasto Livro, um único Livro infinito. A hipertextualidade é apenas um dos nomes dessa incessante circulação dos textos sem a qual a literatura não valeria a pena (GENETTE, 2006. p. 48).

De fato, essa é a matéria viva do arquivo borgeano, no qual não há esquecimento, já que todas as leituras e as leituras das leituras formam textualmente o escritor que as traduz ao mundo, reinscrevendo-as na grande narrativa humana. A proposição do teórico parece corroborar com o afastamento do caráter gnóstico da relação entre Borges e a mística judaica. A busca do Verbo, para ele, talvez seja apenas um jogo literário que atravessa sua noção de literariedade, para citar Genette.

Nesse paradoxo do uso da palavra sagrada para a articulação da lógica narrativa, a Kabbalah se afigura como um fascínio sobre Borges. Ela pode conter as respostas, mais que um caminho de busca por metáforas e jogos discursivos. O papel do leitor na trama narrativa borgeana é fundamental, já que é o próprio espelhamento do autor: um tradutor de um mosaico de outros textos e citações. No entanto, o universo judaico é também tema de sua obra. Contos como A morte e a bússola, Rosa de paracelso, Ruínas circulares, A loteria em Babilônia, A escritura de Deus, assim como Milagre secreto e $O$ aleph, apenas para citar alguns, além de diversos poemas, são 
alguns exemplos. Porém, não nos parece que a sua seja uma luta contra a amnésia da Shoah ${ }^{8}$; Borges fabula um sujeito em deslocamentos espaciais e o localiza em um tempo vertical, em um corredor de espelhos cujos rostos mudam, mas contribuem com um mesmo destino de um sujeito uno. Sua proposta não é política, mas revela o desconhecimento do sujeito sobre as leis do Universo que o coloca em uma busca pelo catálogo dos catálogos, pelo nome de Deus.

O que para Borges é, talvez, apenas um jogo narrativo revela a Sabedoria da qual se utiliza para forjar os deslocamentos aos quais Nascimento se referira anteriormente, em uma estética da poética judaica. Em História dos ecos de um nome sua busca através da linguagem, cara aos cabalistas, se afigura ao nos lembrar o episódio em que Moisés pergunta ao Criador seu nome e Este lhe responde que "é o que é" e assim cita o comentário de Maggid de Mesritch, para quem o "eu" só poderia ser usado pelo Criador e, em uma nota de rodapé aponta para Buber em uma clara relação com o conto O milagre secreto ${ }^{9}$ : "Buber (Was is der Mensch?, 1938) escreve que viver é penetrar numa estranha moradia do espírito, cujo chão é o tabuleiro em que jogamos um jogo inevitável e desconhecido contra um adversário cambiante e às vezes terrível" (p. 189), nós mesmos, quiçá.

Se pensamos a metafísica como ramo da literatura fantástica, não nos distanciamos em apontar a fé como um elemento fantástico na obra de Borges. Milagre secreto é um desses exemplos, que dialogam com a tese de Ruth Fine (2012) ao observar o "lúcido tratamento borgeano do paradigma da fé como fenômeno histórico-cultural universal" (p. 10). O paradoxo do ceticismo de Jaromir Hladík, que pede um milagre e o recebe abre espaço a

\footnotetext{
${ }^{8}$ Nascimento (2009) trata de tal questão e narrativas literárias fílmicas que se apontam como um resgate da memória da Shoá.

Todas as citações de 0 milagre secreto se ferem à seguinte edição: BORGES, Jorge Luis. El milagro secreto. In: _. Ficciones. 6. ed. Barcelona: Debolsillo, 2014. p. 173-184 - e seguirão apenas com a indicação do número de página.
}

um universo fantástico no qual reconhece a existência de Deus. Nesse sentido, há uma transição entre os dois universos narrativos (o real/ histórico com a invasão nazista em Praga e o fantástico com a concessão do milagre) que são apresentados pelo narrador sob o mesmo foco narrativo, deixando ao protagonista a aceitação do divino e ao leitor o questionamento do inefável exercício de tradução da fé.

O Milagre secreto narra os últimos dias do escritor judeu, Jaromir Hladik, que será fuzilado pelo exército nazista na invasão de Praga, em 1939. Por suas raízes, indubitavelmente judaicas, é conduzido a uma prisão onde aguardará a sua morte por fuzilamento. A personagem parece antecipar os acontecimentos da narrativa ao sonhar ser o primogênito de uma das duas célebres famílias que disputam uma partida de xadrez, cujo jogo não sabe as regras. Diante do desespero com a morte iminente, pede a Deus que lhe seja concedido o prazo de um ano para concluir seu drama, Os inimigos. Tal mitologia quiçá se justifique posteriormente no texto El simulacro, do livro El hacedor: "la historia es increíble pero ocurrió y acaso no una vez sino muchas, con distintos actores y con diferencias locales. En ella está la cifra perfecta de una época irreal y es como el reflejo de un sueño o como aquel drama en el drama, que se ve en Hamlet" (2001. p. 24).

A realidade no conto é invadida pela situação fantástica da realização de tal pedido. À personagem é concedido um ano para terminar sua obra, com a estagnação do espaço físico. O tempo, que estava parado, retorna ao seu devir humano e Jaromir Hladík é morto pela tropa de fuzilamento:

Dió término a su drama: no le faltaba ya resolver sino un solo epíteto. Lo encontró; la gota de agua resbaló em su mejilla. Inició un grito enloquecido, movió la cara, la cuádruple descarga lo derribó

Jaromir Hladík, murió el veintinueve de marzo, a las nueve y dos minutos de la mañana (p. 183) 
No ensaio "O tempo circular" (2010), originalmente publicado em 1936, Borges trata da noção do eterno retorno, tão presente em suas obras e amplamente discutida com seu par, Bioy Casares. Nele, a proposição é de que as repetições são ciclos similares (não há novidades - Eclesiastes), não idênticos, e nelas (nas repetições) compreendemos as diferenças. $O$ presente é um lapso e o "único destino possível, a história universal, é a de um só homem" (p. 80).

No conto há uma subversão no tempo cronológico; a noção de tempo é reordenada quando Jaromir se conecta a seu Deus, que é o Tempo, o Universo e o Verbo. A epígrafe nos remete ao Corão, e desestabiliza o leitor que não compreendeu que o Verbo, logo, o Deus, é o mesmo. Nesse jogo de espelhos, Jaromir é também personagem da novela Der Golem citada pelo autor em Cuando la ficción vive la ficción (1990) ${ }^{10}$, sobre a qual diz ser "la historia de un sueño: en ese sueño hay sueños; en esos sueños (creo) otros sueños" (s.p.). Essa arquitetura circular coloca as narrativas nas narrativas, o sonho de Der Golem no sonho de Jaromir Hladík, a criação. Ainda nesse texto encerra Borges com a seguinte ponderação creditada a Schopenhauer: "escribió sueños que los sueños y la vigilia eran hojas de un mismo libro y que leerlas en orden era vivir, y hojearlas, soñar. Cuadros dentro de cuadros, libros que se desdoblan en outros libros, nos ayudan a intuir esa identidad" (s.p).

O fantástico, na concretização do milagre, assim como a própria trajetória de Jaromir Hladík estão inscritos na tradição da história e são narrados com dados quase precisos por um narrador que transita nesses dois universos, balizado por fontes documentais. Além das suratas II 258, 259 e 261 referidas na epígrafe, no Pentateuco, livro de Reis $(2,20)$ é narrada

${ }^{10}$ Nesse breve ensaio, Borges trata da ficção representada na ficção ao descrever uma lata que reproduzia cujas histórias são lidas pelo próprio Quixote, assim como Hamlet que encena (A ratoeira) Hamlet. a história de Ezequias, rei de Judá, que adoece e ora a Deus pedindo sua cura; Ele a concede, dando-lhe quinze anos a mais de vida. A apreensão do tempo é então revelada no livro sagrado como um evento natural: "Então o profeta Isaías clamou ao Senhor; e fez voltar a sombra dez graus atrás, pelos graus que tinha declinado no relógio de sol de Acaz" (BÍBLIA, 2012, p. 422) e assim também o é no conto.

Hladík, atordoado pela condenação, esquece ou não sabe quem é, a que família e tradição pertence verdadeiramente. Em 1951 escreveria Borges: "a história universal é uma Escritura Sagrada que deciframos e escrevemos de forma incerta, e na qual também nos escrevem" e ainda, referindo-se a Bloy, disse: "Não há na Terra um ser humano capaz de declarar quem é. Ninguém sabe o que veio fazer neste mundo, a que correspondem seus atos, seus sentimentos, suas ideias, nem qual seu verdadeiro nome, seu imperecível Nome no registro da Luz" (BORGES, 2007, p. 136).

Esta chave só é revelada a Jaromir através dos sonhos, que servirão como um espelho da totalidade de sua existência; o tempo não se detém somente para ele, porque ele é o próprio povo ao qual pertence, o tempo se detém para que conclua algo tão caro à cultura judaica, a palavra, a fé inscrita na tradição. No transcorrer da narrativa, são dois os sonhos do poeta e é neste estado que a consciência de sua tradição, de sua anterioridade parece transcender o seu papel individual de um homem condenado à morte e abrir-se a um estar no mundo coeso e contínuo: é o primogênito de uma das famílias e este é o seu momento de jogar; e será esta a ação, a de um sujeito que ingenuamente não compreende a grandiosidade do que lhe foi concedido.

A personagem sonha com uma partida de xadrez "travada havia muitos séculos" (p. 175), a lembrança de um duelo não entre dois indivíduos, mas entre duas famílias. No sonho, Hladík é "o primogênito de uma das famílias hostis" (p. 175) impulsionado pelo tempo que corria na areia dos relógios, anunciando sua vez de jogar, mas ele não recordava das leis do jogo. Hladík é 
de origem judaica e o prêmio da partida é "enorme e talvez infinito" (p. 175) como o conflito "travado há muitos séculos" (p. 175) e que ainda hoje é um embate, especula-se, por ser reconhecido como o povo de Deus.

Seu destino é anunciado no sonho e naquele amanhecer em que as tropas do Terceiro Reich entraram em Praga, saberia em poucos dias da execução fixada para 29 de março, às 9 h. Saberia do milagre, da detenção do tempo, mas não saberia o futuro, tampouco jamais compreendera o passado. No poema El ajedrez, uma das estrofes diz: "Cuando los jugadores se haya ido/ cuando el tiempo los haya consumido/ ciertamente no habrá cesado el rito" (2001. p. 71-72). O presente é o que pode apreender Jaromir, ele é o criador de seu próprio drama, um simulacro de si. "Ahora estoy em la noche del veintidós; mientras dure esta noche (y seis noches más) soy invulnerable, inmortal” (p. 177), pensará.

A guerra é travada entre dois povos que talvez sigam o mesmo Deus e que se perpetua no tempo. Vítimas e vitimados são verticalmente o mesmo sujeito que joga eternamente a partida. Tal aproximação parece esclarecer o sonho e apresentar Hladík como real representante de uma das famílias do passado, que no momento da narrativa está diante de outra disputa, que é a mesma, ser perseguido pelo que é, judeu. 0 elemento fantástico no conto é apresentado numa relação entre o sonho e a realidade, numa dicotomia que revela a disputa que se repete no tempo e na história.

Enquanto é mantido preso à espera de sua execução, Hladík "morreu centenas de mortes", em "execuções imaginárias" (p. 177) acreditando adiála ao fabular. No entanto, ao imaginar sua execução acaba por entender a Verdadeira profecia e inicia o reconhecimento da passagem incansável do tempo. Se conecta a seu Deus, sentindo-se imortal até as $9 \mathrm{~h}$ do dia 29. Na véspera de sua morte, Hladik tenta justificar sua existência voltando-se à tragédia inacabada "Os inimigos". "Ele intuía" ser tal tragédia "a invenção mais apta para dissimular seus defeitos e exercitar suas felicidades", bem como ser "a possibilidade de resgatar (...) o fundamental de sua vida" (p. 180). Hladik passa a acreditar, após reconhecer que realmente irá morrer, que sua vida precisa ser justificada, e nele parece acender algo inexistente, que o impulsiona a falar com Deus, pedindo-lhe, como prova de suas existências, um milagre.

É de Maimônides, filósofo judeu da Espanha medieval, o entendimento de que Moisés foi o tradutor da palavra divina ao povo de Israel. Para ele, a profecia pode acontecer de duas formas: no sonho, quando aquele que a recebe não está consciente ou através de uma visão, quando aquele que a recebe está desperto. A diferença, como se percebe, está na clareza da comunicação profética, como aconteceu para Hladik, o sonho que tem no início do conto lhe é incompreensível, mas revelador de seu destino. Seu Deus lhe lembra da passagem do tempo e de seu estar no mundo, que justificaria sua fé.

Maimônides explica uma comparação feita pelos sábios judeus (em Berechit Rabba Cap. XVII ${ }^{11}$ ) que comparam o sonho com uma fruta verde diante da verdadeira Profecia, essa uma fruta madura, com uma mensagem clara e precisa. No primeiro sonho a personagem o compreende como uma mensagem. No segundo sonho, somos apresentados a uma cena "realista", não há uma proposta de estranhamento, de mudança de realidades, o sonho é nítido e Hladik o vive de modo pleno, como em uma profecia, tal qual expõe o tese maimônica.

un pasaje de la Escritura que dice: "Si hubiera entre vosotros Profetas, Yo, el Señor, me daré a conocer a él en visión, o le hablaré en un sueño"? (NUM. XII, 6) ¿Dícenos aquí el Señor que la verdadera esencia de la Profecía consiste en una percepción a la que se llega durante el sueño o la visión; la facultad imaginativa adquiere tal eficacia, que ve las cosas como si vinieran de fuera, y las percibe como a través de los sentidos corporales. Estas dos maneras de Profecía, visión y ensueño, encierran todos los grados de la misma (MAIMONIDES, sd. p. 129)

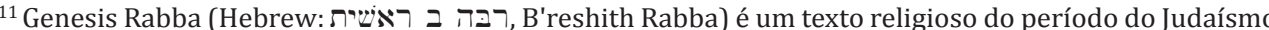
clássico. É uma midrash, compreendendo uma coleção de interpretações rabínicas homiléticas sobre o Livro do Gênesis. 
No segundo sonho, Hladik está em uma das naves da biblioteca de Clementinum e é atendido por um bibliotecário cego com quem trava o seguinte diálogo: "Procuro a Deus", diz Hladik, " - Deus está numa das letras (...) de um dos 400 mil tomos do Clementinum" (p. 131-2), responde o outro. Então, Hladik recebe das mãos de um leitor um atlas, para quem este livro havia sido inútil. Abre-o e, "repentinamente seguro", toca uma das letras num mapa aleatório e ouve uma voz onipresente: "O tempo de seu trabalho foi concedido". Em uma clara Profecia, Deus fala com Hladik no sonho, nítido e preciso, como se acordado estivesse. E segue o narrador: "Recordou que os sonhos dos homens pertencem a Deus e que Maimônides escreveu que são divinas as palavras de um sonho, quando são distintas e claras e não se pode ver quem as disse." (p. 132). Diante do pelotão de fuzilamento, na hora da morte, "o universo físico deteve-se". "Hladik ensaiou um grito, uma sílaba" (p. 182) e compreendeu que o tempo parou. O fantástico acontecia e a Hladik era concedido o tempo de um ano, exatamente como pedira, para poder terminar sua obra, pois Deus praticava para ele um milagre secreto. Entre perplexo e resignado, Hladik alcança o agradecimento e no rigor da memória reelabora o drama. No ensaio A Cabala, a perpetuação da oralidade parece resolver-se:

Quando pensamos nas palavras, pensamos historicamente que as palavras foram no início som, e depois chegaram a ser letras. Na cabala (que significa recepção, tradição), porém, supõe-se que as letras são anteriores, que as letras foram os instrumentos de Deus, não as palavras significadas pelas letras. É como se se pensasse que a escrita, contra toda experiência, fosse anterior à dicção das palavras. Nesse caso, nada é casual na Escritura: tudo precisa estar determinado (BORGES, 2011. p. 187).

O fantástico, para Todorov, é o meio termo entre fantasia e realismo. $\mathrm{Na}$ fantasia tudo é mágico, o universo se apresenta e o aceitamos com suas irrealidades lógicas ou não. No realismo, há o rigoroso e presunçoso compromisso com a representação da realidade em sua mais possível realização. Assim, no fantástico teríamos o meio termo, pois não sabemos se o que se presenciou é fantasia, por possuir características irreais, mas também não podemos admitir que não seja real, porque é possível de ser explicado com veracidade. Esta brecha entre os dois universos se funda na fé, na tradição, no entrecruzamento de narrativas que fabulam a grande narrativa humana. 0 leitor desacredita na própria realidade e se confunde com a ficção.

Para Ruth Fine,

Es una paradoja que, a fin de que el milagro secreto sea plausible, exige la fe del lector, como también, simultáneamente, su duda o esceptismo respecto de ese único hecho quizás sobrenatural: allí y sólo allí, en lo uno y lo otro, o ni en lo uno ni lo otro, habita lo fantástico como ejercicio de fe lectora (FINE, 2015. p. 7).

O leitor e a leitura são peças fundamentais na teoria narrativa de Borges, que opera o foco narrativo a partir dessas instâncias, do pacto de um fantástico "documentado" e de uma realidade histórica "fabulada" que jogam com a fé e o ceticismo do leitor.

Em Formas Breves, Ricardo Piglia desenvolve a tese de que os contos de Borges narram duas histórias de modo que a história 2, cifrada, é forjada nos interstícios da história 1, clara e objetiva. Para o crítico argentino, a história 2 é a própria forma do conto. Neste sentido, recuperamos o entendimento de Maimônides, citado diretamente pelo narrador de o Milagre, sobre o que seja profecia. Como vimos, para o filósofo medieval, o sonho é um dos modos do homem falar diretamente com Deus (p. 134). Lembremo-nos que o fazer literário do bibliotecário é um exercício constante de metalinguagem, no qual a escritura é a revelação de uma leitura traduzida ao leitor. Atentos a isso, relacionamos o sonho como um espaço transcendente onde o reconhecimento da fé se dá com a revelação do Criador a suas criaturas; o 
fantástico está impresso no encontro da letra sagrada, a reconexão entre o mundo vivido e o imaginado.

A música, os estados de felicidade, a mitologia, os rostos trabalhados pelo tempo, certos crepúsculos e certos lugares querem nos dizer algo, ou algo disseram que não deveríamos ter perdido, ou estão a ponto de dizer algo; essa iminência de uma revelação que não se produz é, quem sabe, o fato estético (BORGES, 2007, p. 12).

Este excerto de A muralha e os livros corrobora com o entendimento de Sosnowski, para quem o

estado universal é explicado como produto de uma inteligência divina, infinita e todo-poderosa cujos alcances a razão deverá acatar se deseja permanecer dentro duma concepção teológica. Borges não aceita esse limite e por isso busca novas aberturas através da linguagem. (1991, p. 42),

O interesse não é teológico senão literário. Porém, seu fascínio, é inegável:

Um livro impenetrável à contingência, um mecanismo de propósitos infinitos, de variações infalíveis, de revelações que espreitam, de superposições de luz, como não interrogá-lo até o absurdo, até a prolixidade numérica, como fez a Cabala? (BORGES, 2008. p. 64)

A fábula narrativa se confundirá com a percepção da realidade do leitor e, como tal, do tradutor. Apoiados no Kotel, os sujeitos lamentam e conversam com seu Deus em um labor silencioso, que a tecnologia transmite $24 \mathrm{~h}$ ao vivo pela internet, que ultrapassa a imagem que não capta o clamor que talvez o identifique como o de um povo inteiro. Tal prece é também a do outro, que busca cegamente a articulação das letras nas inumeráveis palavras dos milhares de tomos da biblioteca de Babel. Jaromir não sabe das preferências literárias de seu Deus, mas as discorre no discreto labirinto, na palavra sonora. Se tudo já está, se o Universo é a Biblioteca, Los enemigos são uma tradução de Jaromir, articulado em um jogo paradoxal entre fé e razão.

O narrador não comprova se o milagre ocorreu ou não, pode ter sido apenas uma ilusão provocada pelo desespero com a premência da morte, mas a articulação da narração é logicamente elaborada e conta com a prerrogativa de que somos (como invenções do $\mathrm{Poe}^{12}$ ) leitores desconfiados.

\section{Referências}

BÍBLIA. Português. Bíblia sagrada. São Paulo: Ave Maria, 2012. Edição Claretiana. BORGES, Jorge Luis. Yo, judío. In: Megáfono, Buenos Aires, v. 3. n 12, p. 60, abr. 1934.

. Do culto aos livros. In: Outras inquisições. São Paulo: Companhia das Letras: 2007. p. 131-136.

. O conto policial. In: Borges oral \& Sete noites. São Paulo: Companhia das Letras: 2011. p. 51-65.

. Uma vindicação da Cabala. In: Discussão. São Paulo: Companhia das Letras, 2008 p. 60-64.

A Cabala. In: Borges oral \& Sete noites. São Paulo: Companhia das Letras, 2011. p. 182-196.

A memória de Shakespeare. In: Nove ensaios dantescos \& A memória de Shakespeare. São Paulo: Companhia das Letras, 2011. p. 92-102.

. O tempo circular. In: História da eternidade. São Paulo: Companhia das Letras, 2010. p. 76-81.

. História dos ecos de um nome. In: Outras inquisições. São Paulo: Companhia das Letras: 2007. p. 187-191.

. El milagro secreto. In: Ficciones. 6. ed. Barcelona: Debolsillo, 2014. p. 173-184.

La biblioteca de Babel. In: Ficciones. 6. ed. Barcelona: Debolsillo, 2014. p. 88-100. El hacedor. Buenos Aires: La Nación, 1996.

${ }^{12}$ No ensaio "O conto policial”, diz Borges: "esses não eram treinados como nós, não eram uma invenção de Poe como nós somos" (2011. p. 60). 
Cuando la ficción vive la ficción. In: Textos cautivos. Barcelona: Tusquets, 1990.

FINE, Ruth. Borges y las paradojas de la fe. In: Criterio Digital, Buenos Aires, n. 2413, 2015.

La fe en Borges. Palestra na UFRGS, 2015.

FOUCAULT, Michael. As palavras e as coisas. 8. ed. São Paulo: Martins Fontes, 2002.

GENETTE, Gerard. Palimpsestos: a literatura de segunda mão. Belo Horizonte: UFMG, 2006.

NASCIMENTO, Lesley. Borges e outros rabinos. Belo Horizonte: UFMG, 2013.

PIGLIA, Ricardo. Ideología y ficción en Borges. In: Punto de Vista, Buenos Aires, año 2, n. 5. p. 3-6, 1979.

SCHOLEM, Gershom. A cabala e seu simbolismo. 2. ed. São Paulo: Perspectiva, 2012. SOSNOWSKI, Saúl. Borges e a Cabala: a busca do verbo. São Paulo: Perspectiva, 1991. TODOROV, Tzvetan. Introducción a la literatura fantástica. Buenos Aires: Paidós, 2006.

Recebido em 10/05/2016.

Aceito em 15/07/2016 